\title{
A ANTECIPAÇÃO DE UM APOCALIPSE OU DE UMA PROMESSA
}

Luiz Costa Lima

(PUC-Rio/UERJ/CNPq)

\author{
RADÜNZ, Dennis. OSSAMA \\ Letras Contemporâneas, Curitiba, 2016
}

O colega e amigo Nabil Araújo, ao saber que tenho um livro em preparo, ofereceu-se para publicar uma parte sua, na revista Matraga. A gentileza não pôde ser retribuída porque o que já está escrito ainda não foi sujeito à devida revisão. Como um pedreiro consciente de seu ofício, não considero uma parede levantada senão depois de algumas tantas provas e cuidados. Lembrei-me então de uma resenha que publicara há pouco. Intuí que servia à função fosse por seu tom agressivo, fosse por divulgar um livro de autor promissor. Mas logo me indago: por que o tom agressivo é tomado como um dado louvável e, a seguir, qual sua relação com a promessa que se divulga? Ambos os qualificativos precisam ser justificados. E isso constituirá literalmente um pré-texto.

Quanto ao primeiro, porque, na verdade, vivemos um momento extremamente sombrio, e não só na UERJ, abandonada por um governo que acumula jóias e prebendas para seus apaniguados, enquanto não tem meios para pagar seus servidores, como no sistema educacional do país. Mas tampouco só por ele. A reação generalizada contra a fraude representada pela vitória de Trump, nos Estados Unidos, mostra que aí chegamos ao auge de uma escalada. A escalada do desastre, pela qual é responsável uma parcela de nós mesmos. E isso a tal ponto que nos últimos dias, a partir do momento em que tomei conhecimento de uma pequena bibliografia sobre a arte da dissimulação na política do século XVII, comecei a considerar se não valeria a pena interromper a série interminável de pesquisas sobre temas literários, para repensar a sua base. Qual base? Aquela que, contrapondo-se à concepção da literatura como um prolongamento da realidade, a pensava como seu polo oposto. Assim, se estou cansado de 
conceber a literatura como produto da interrelação entre verossimilhança e necessidade (os velhos termos da Póetica aristotélica), pensados em função de um terceiro termo, a realidade, em troca a concepção mesma de realidade mantinha um perfil que começo a suspeitar envelhecido. Este perfil tem consistido em declarar que por realidade entendemos a combinação de dados perceptuais, por extensão sensíveis, com a coloração valorativa que tais dados recebem. O que vale dizer: a realidade não é simplesmente o que nos cerca e se põe à nossa frente, senão o peso ou valor que concedemos ao circundante.

Ora, é preocupante a insistência com que essa concepção começa a ser transtornada. O que chamava há pouco de nossos tempos sombrios tem o seguinte pressuposto: assim como, no caso do polo literário, a aproximação entre verossímil e necessário com a realidade se faz através da exploração de um certo fictício, assim também, no polo da realidade, a relação entre o dado e a coloração valorativa é feita por um plano também fictício. Se chamo aquele de fictício 1 e este de fictício 2, tenho melhores condições de distingui-los, a partir da base comum definida na Metafísica aristotélica: "Entendo por fictício o que é aduzido de modo forçado para sustentar uma hipótese" (Met. XIII, 1082b 3-4). O fictício internalizado na composição do objeto literário não pretende ser verdadeiro, senão que se enraíza no verossímil para que este melhor passe à condição de necessário. Já o fictício 2, sendo o meio pelo qual os fatos (combinação do dado com a coloração valorativa) da realidade são transmitidos, isto é, convertidos em comunicáveis, pretende fortemente ser verdadeiro. É neste sentido que recentemente me chamou a atenção a expressão usada por um articulista norte-americano a propósito da influência nefasta estabelecida em todo o mundo pela televisão. Ele a chamava de reality-television. Proponho traduzi-la por tele-realidade. Pela expressão quer-se dizer: as redes televisivas a tal ponto forjam "o que sucedeu" e assim preparam o que há de suceder, que substituem o que seria a realidade por um fictício da realidade.

Bem, na impossibilidade de ir muito adiante, relaciono a explicação que dava ao qualificativo "tom agressivo" com o qualificativo seguinte: a divulgação de alguém promissor. Os dois qualificativos se combinam, com independência de sua posição na frase. Como assim? É mesmo porque vivemos sob a cobertura do fictício 2 que se torna praticamente nula a possibilidade de divulgação do objeto em cuja composição entra o fictício 1 .

Alguém poderá dizer que essa é uma maneira complicada de expli- 
car que, nos últimos anos, a literatura perdeu seu veículo de expansão, os suplementos. Se for uma maneira complicada, desculpem. Mas, de todo modo, meu interesse não é apenas denunciar a perda para a literatura. O desaparecimento dos suplementos tem um alcance muito maior: ele revela que o fictício 2 não tem interesse em difundir a reflexão por escrito. Quero portanto dizer: para que o fictício 2 assuma uma força de propagação cada vez mas larga é preciso que o que não seja conversível em técnica seja posto de lado, enterrado, esquecido. Daí, por um lado, a multiplicação dos headphones, dos celulares e tablets e, por outro, a restrição das editoras que já foram de qualidade em divulgadoras de obras de qualidade apenas mediana, possíveis candidatas a uma grande vendagem.

Ao terminar essa abertura ao que antes fora uma pequena resenha, me pergunto se não fiz um anúncio quase apocalíptico. É possível que $\operatorname{sim}$. Que remédio teríamos contra ele? Eis uma pergunta que não sei responder. O apocalipse por si em nada me agrada. Mas, se devo recorrer a ele para alertar o leitor do que chamei de fictício 2, não hesito em fazê-lo. Mais do que isso: agradeço a Nabil ter-me levado a fazê-lo.

***

Em 1917, com o "urinol invertido", ironicamente intitulado de FONTE, então ainda chamado de "objet trouvé", Marcel Duchamp iniciava o que, a partir dos anos de 1960, se tornaria difundido como "ready-made". O que começara como ironia e agressão contra a arte cultuada, converte-se no meio para o conjunção da arte com o mercado. Serializada por Andy Warhol, a imagem banal converte-se no ícone da pop art. Ao menos para os que a seguem, a arte passou a ser outra manifestação da cultura.

É com agradável surpresa que vejo um jovem poeta catarinense contrapor-se à arte comercializada, transformada em uma manifestação a mais de ganhar dinheiro. Refiro-me ao pequeno OSSAMA (Letras Contemporâneas, Curitiba, 2016), de Dennis Radünz. A partir de um prévio “Exumação 1991”, onde a palavra 'corpo' se desintegra e enterra em linhas de 'terra', a obsessão com o ready-made assola a cabeça do poeta. Mas, se é cabível falar em obsessão, é ela de sentido oposto àquele que foi legitimado por certa pintura norte-americana. Assim se revela desde o "cidades sedadas", de que transcrevo a primeira parte: "Os inframericanos - a sobrecriatura / - escapas - capturas - as patrulhas de procuras / - as provisões de previsão do tempo exposto / entre os nervos do espaço - nas 
póvoas ímpias - blindados - blecautes - blocausses - / os silenciários sedados - os suicidados - (...) e a a quarta - feira seguinte pola manhaã I topamos aves a que chamam fura buchos (....)”.

Os versos seguem uma ordem temporal invertida - desde os dias de hoje para bem antes. O termo de abertura - "os inframericanos" - salta, na estrofe seguinte, para a transcrição da CARTA de Caminha. Entre a abertura e a passagem da CARTA, a tematização temporal invertida configura um anti-ready-made. Se a marca da inscrição mercadológica rasgara a separação entre a imagem-com-arte e a imagem banalizada, o anti-ready-made não visa a recuperar a glória perdida da arte, mas assinalar que os termos "progresso", "utopia" se tornaram assombrações e fantoches. Já não cabem nos dicionários porque aqui e agora só entram negócios.

$\mathrm{O}$ anti-ready-made fala de um presente em que se destaca o "olha-podrida". Trata-se de uma transposição irônica-grotesca do cozido espanhol, que apresenta o poema cujo subtítulo é "Dos suicidados pelas ditaduras" - "tomam corpo / de um talho a outro talho / (e tão entibiados) os desaparecidos / deitam os lanhos em oliva / de um dente a outro dente / ou fumegam ou formigam / no fundo da olha-podrida". Mas seria arbitrário que, do mundo capitalista globalizado, o anti-ready-made destacasse apenas as ditaduras. Não é preciso que elas estejam formalmente vigentes para que em "Liquidação" vigore a "mercadoria" - em seu império, "os sedados subsolam / em beberagens repentinas / ou insonoros se desossam / entre os dormidos da ermida" - e a "consumação", onde "(se compra) silêncio", "e (se escuta) nas torres/ os sinais do intransmissível".

Pelo anti-ready-made não se restabelece o que foi posto fora da vida senão que o circuito da vida é agora feito por jorro de sémens e insumos pelos quais a mercancia passa a cruzar (no duplo sentido do verbo). E o que circula em vida deixa de pertencer à ordem do orgânico para fermentar em uma perversa science-fiction: "como se carros começassem a nascer-nos as arcadas / e esses ossos de mandíbula absorvessem-nos os dentes". Por isso do "astronauta austral" se diz que "naturalizou-se cidadão contrarromano", assim como o final de "museu-mundo" "recolhe o que sobrou do sapiens (...): o dedo de galileu, o cérebro de Einstein / o último exemplar / de ÉTICA a NICÔMACO”. Pela compra e venda, o mundo assume outra direção.

Na segunda parte de OSSANA, "Datação por luminescência", o ossário geral assume dimensão mais local, como se tematizasse o mundo mais próximo do poeta. Daí que um poema fale da velha máquina Oli- 
vetti, de poetas nacionais, de sua própria ascendência familiar. Contento-me em destacar o "Cinquenta cruzados novos", de que apenas transcrevo a notável primeira estrofe: "Os cruzados novos, custo caro de carlos, / quando circularam uma soma de ocasos / consumida em cruza de papéis e moeda: / o gasto do rosto no inconsútil da cédula".

Um mestre da cultura do livro, o poeta Drummond, se torna objeto de outra ascendência. Seus pais mineiros foram substituídos por uma cruza de papel e moeda. E o rosto do poeta foi gasto no papel da cédula em que circula. Seu apreço se confunde com o valor monetário que o socializa.

Embora seja muito difícil falar-se com acerto e, ademais, como sou obrigado a aqui fazer, telegraficamente, de uma linguagem que se antecipa, estive certo que seria algo de criminoso deixar de fazê-lo. Quando falo de linguagem que se antecipa a si mesma estou declarando que a mentação do anti-ready-made, em seu inaugurador, Dennis Radünz, ainda vai muito além da formulação que a cumpre. Pois OSSAMA constitui um exemplar que suponho raríssimo de um livro que, antes de se tornar obra-prima, assim já se anuncia.

Recebido em: 05/06/2017

Aceito em: 06/06/2017 